\title{
Did past economic prosperity affect the health related quality of life predictors? A longitudinal study on a representative sample of Slovenian family medicine patients
}

\author{
Anja Cerne, Igor Svab, Janko Kersnik and Polona Selic ${ }^{*}$
}

\begin{abstract}
Background: Health related quality of life (HRQOL) as an important measure of medical outcomes has been shown to be associated with demographic factors and the most common mental and chronic somatic diseases. This study's aim was to identify factors predicting changes in $\mathrm{HRQOL}$ over a follow-up period in a representative sample of Slovenian family medicine patients.

Methods: In a longitudinal multi-centred study between 2003 and 2005, data were collected from 1118 consecutive attendees from 60 family medicine practices in Slovenia on quality of life, socio-demographic factors and the presence of mental disorders, with follow-up after 6 and 24 months. Retrospective information on chronic diseases was obtained from patients' health records. In three time-sequential multiple linear regression models, data on 601 patients (53.8\%) was analysed to determine factors associated with each component score of quality of life.

Results: At baseline the patients were 48.58 ( $S E=0.58$ ) years of age, over half were women $(386(64.2 \%))$ and most were Slovenian (548 (91.2\%)). Quality of life was seen to improve over the two-year period. Factors significantly and consistently associated with a better mental component score of quality of life were social support, satisfactory circumstances in patients' household and absence of anxiety. Major life events in the past year and depression were shown to be risk factors for mental and physical components, while level of education, absence of long-term disability and chronic pain were identified as predictors of the physical component.

Conclusions: Detection and successful treatment of depression and anxiety has a potential to lead to improved quality of life in family medicine attendees; family physicians should be alert for the early onset of these conditions, knowing that symptoms of chronic pain, depression and anxiety often overlap in patients. Poorly educated patients and those lacking social support and/or satisfactory household circumstances should be recognised and empowered, and appropriate coping mechanisms should be introduced.
\end{abstract}

Keywords: Quality of life, Family medicine, Psychosocial determinants, Depression, Stress, Anxiety

\footnotetext{
*Correspondence: polona.selic@siol.net

Department of Family Medicine, Faculty of Medicine, University of Ljubljana,

Poljanski nasip 58, Ljubljana, Slovenia
} 


\section{Background}

Nowadays, family physicians encounter more patients suffering from more than one chronic condition than they did in the past [1]. Since a cure for such patients is often not possible, an important goal of medical practice has become improving the patients` quality of life (QOL) [2]. QOL is an individual's perception of their position in life in the context of the culture and value system in which they live, related to their goals, expectations, standards and concerns $[3,4]$. As an outcome measure it has been increasingly used to evaluate the outcomes of patients with chronic diseases $[5,6]$. Health-related quality of life (HRQOL) has been shown to be even more suitable for use in medicine, as it focuses on health related expectations. Generally, HRQOL is interpreted as the impact that health conditions and symptoms have on an individual's quality of life [7]. Given that, components of HRQOL are physical functioning, mental health, physical pain, general health, vitality, and social functioning $[8,9]$.

A substantial body of research has paid interest to various diseases which could be associated with HRQOL. Common mental disorders such as affective and anxiety disorders cause distress and disability in several domains of life, and consequently have a significant effect on HRQOL [10-14]. Studies in different patient populations have also found patients diagnosed with one or more somatic diseases [15], those with multiple diseases [16], or those with selfreported long-standing illness [17] to have a lower HRQOL than the general population. HRQOL is inversely related to the number of diseases in a patient [18]. As expected, patients with diseases that produce more symptoms, e.g. osteoarthritis, congestive heart failure, and chronic obstructive pulmonary disease, have lower levels of HRQOL [1]. Aside from disease, certain demographic and social characteristics of the patient are also associated with HRQOL, i.e. a higher age [15], female gender [19,20], lower educational level, unemployment and lower income [21-23].

Since most of the studies that have been performed so far were cross-sectional, little is known about changes in HRQOL over several years, or about factors predicting a change in HRQOL. The aim of this study was to identify the factors which predict a change in HRQOL over a longer time interval.

\section{Methods}

\section{Procedure and participants}

In 2003, family physicians (general practitioners (GPs)) in 60 family medicine practices in Slovenia each recruited 10-20 consecutive patients, collected data, and reviewed their status after 6 and 24 months. The participating family medicine practices were selected from both urban and rural settings, and served a population with diverse socioeconomic and ethnic characteristics [24]. The inclusion criterion for the patients was age 18-75 years; the exclusion criteria were poor knowledge of Slovene, a major mental disorder, or terminal disease. Patient consent was obtained and appropriate steps were taken to maintain patient confidentiality.

In 2009 additional data on chronic somatic diseases were gathered from the patients' records for the time period from 2003 to 2009, so that multi-morbidity and its patterns in these patients could be assessed and analysed. The GPs were asked to review the medical records of the subjects who were included in the original prospective cohort study on depression $[24,25]$ and to note the presence of any of the somatic diseases included in the multi-morbidity questionnaire.

Of 1388 invited patients, 1118 agreed to participate, an initial response rate of $80.5 \%$; the main reason for refusal was lack of time. There were no statistically significant differences in gender and age between people who were and those who were not willing to enter the study. After 6 and 24 months, there were 1037 (92.7\%) and 784 (70.1\%) participating patients, respectively. In the multimorbidity part of the trial in 2009, data was collected for $925(82.7 \%)$ of the initially recruited patients. The study flowchart is presented in Figure 1.

After excluding questionnaires with missing data, 601 questionnaires (53.8\%) were analysed for this study. There were no statistically significant differences in any of the analysed variables of the initial cohort, aside from gender (female 63.4\% vs. 64.2\%, $\mathrm{p}<0.05$ ).

The National Medical Ethics Committee of the Republic of Slovenia approved the protocols of the studies Predicting the Occurrence of Depression in Primary Health Care and The Acceptability of a Multi-factor Rating Scale for Predicting Depression in Family Medicine.

\section{Measures}

Information on the socio-demographic characteristics of the participants was collected using standardized questionnaires [24]. Overall health status and HRQOL was assessed by the SF-12 questionnaire [26], resulting in a Mental Component Score (MSC) and Physical Component Score (PSC), which were both defined as dependent variables in this study. Mood was examined using the Depression Section of the Composite International Diagnostic Interview (CIDI) [27], which provided psychiatric diagnoses based on symptoms experienced in the last six months, according to the Diagnostic and Statistical Manual of Mental Disorders (DSM-IV) criteria. Anxiety disorders were examined using the Patient Health Questionnaire (PHQ) [28], a brief questionnaire designed to assess DSM-IV, other anxiety disorders and panic disorder. Alcohol use was assessed by the World Health Organization Alcohol Use Disorders Identification Test (AUDIT) [29]. All these instruments were adapted for the Slovenian population in the previous research $[24,25]$. 


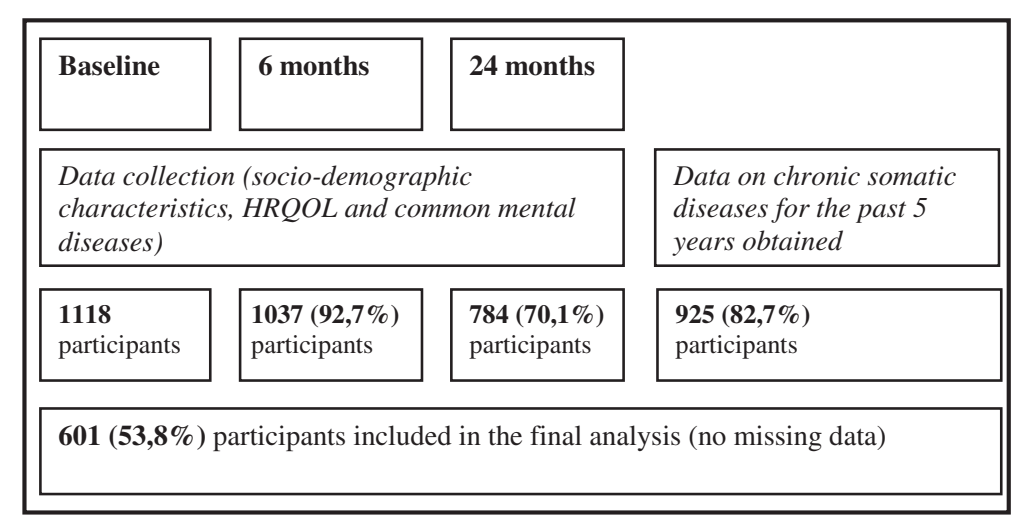

Figure 1 The study flowchart.

The multi-morbidity questionnaire covered most of the common chronic diseases and health problems in the Slovenian adult population [30], i.e. ischemic stroke, dementia, Parkinson's disease, epilepsy, coronary heart disease, malignant disease, chronic pulmonary disease, hypertension, arthritis, poor vision or hearing, chronic pain, chronic bowel disease, ulcers, gastritis, GERD, dysphagia, injury, incontinence or prostate problems, hypo- or hyperthyroidism, hypo- or hyperparathyroidism, hypo- or hyperadrenalism, porphyry and uraemia.

\section{Data analysis}

The sample data were presented by frequency and percentage distribution for categorical variables, and by a mean value and standard deviation for continuous variables. In general, the MCS and PCS of the SF-12 were computed by a linear weighting of the 12 items in the questionnaire. In univariate analyses the associations (i.e. mean comparisons) between the independent variables and the MCS and PCS of HRQOL were calculated. Variables which proved statistically significant on at least two out of three data collections or which had been proven to be associated with MCS and/or PCS in a known body of research were used in multivariable linear regression modelling. A linear regression was conducted to $T_{0}, T_{6}$ and $T_{24}$ sequentially and separately. Multivariate models were performed separately for the MCS and PCS components of HRQOL at the first data collection, after 6 and after 24 months $\left(\mathrm{T}_{0}, \mathrm{~T}_{6}\right.$ or $\left.\mathrm{T}_{24}\right)$, aiming to determine the impact of time on each component of the quality of life. Independent variables included in the modelling process predicting MCS are shown in Table 1, while those predicting PCS are presented in Table 2. Statistical significance was set at $\mathrm{p}<$ 0.05 . The analysis was performed using the statistical package SPSS, version 13.0 (SPSS for Windows, Chicago: SPSS Inc.).

\section{Results}

At baseline, the participants were $48.58(\mathrm{SE}=0.58)$ years of age, more than half were women (386 (64.2\%)), and the majority were of Slovenian origin (548 (91.2\%)). Most had average education (367 (61.1\%) finished high school and $102(17.0 \%)$ achieved college or more) and did not have financial problems (509 (84.7\%) doing 'all right' or better). More demographic characteristics for the period of the study are presented in Table 3.

The social determinants of the patients in the period of the study are shown in Table 4. Of all the participants, 309 (51.4\%) had experienced at least one stressful life event in the past year. The average value of the estimated social support of relatives and friends on a scale from 7 to 21 was 18.8 (18.6-19.0), and the average satisfaction with the patients' own household on a scale from 1 to 5 was 4.3 (4.2-4.3). Of all, 93 (15.5\%) participants were diagnosed depressive, and 49 (8.2\%) were diagnosed with anxiety disorders at baseline. Just over two thirds of the patients $(405(67.4 \%))$ had at least one chronic somatic disease, and about one third (173 $(28.8 \%))$ of the patients were multi-morbid at baseline. Over the time of the study there was a rise in the average number of chronic conditions per patient (from 1.14 to 1.26$)$ and in the percentage of multi-morbid patients (from $28.8 \%$ to $33.4 \%$ ), which was to be expected due to ageing. The multi-morbidity of the patients for the study period is presented in Figure 2.

At the time of inclusion in the study, 317 (52.7\%) of patients reported long term disease or disability, which was a criteria for self-rated health; this number had dropped to $277(46.1 \%)$ at the two year follow-up. The most frequent chronic condition reported was arterial hypertension in 165 patients (27.5\%), followed by chronic pain $(n=122(20.3 \%))$. Self-rated health and health conditions for the study period are presented in Table 5. 
Table 1 Comparison of $\beta$-coefficients at baseline, after 6 and 24 months: Predictors of better mental component score of HRQOL

\begin{tabular}{|c|c|c|c|}
\hline \multirow[t]{2}{*}{ Independent variables } & $\beta(601)$ & $\beta(601)$ & $\beta(601)$ \\
\hline & 0 months & 6 months & 24 months \\
\hline Better PCS & -0.086 & -0.041 & -0.134 \\
\hline Higher age & 0.065 & 0.099 & 0.077 \\
\hline Male gender & 0.105 & 0.072 & 0.100 \\
\hline Higher level of education & 0.006 & -0.060 & -0.045 \\
\hline Better financial status & 0.097 & 0.059 & 0.088 \\
\hline Better circumstances in a household & 0.127 & 0.175 & 0.091 \\
\hline Better social support & 0.159 & 0.133 & 0.099 \\
\hline Stressful life events - present & -0.071 & -0.129 & -0.082 \\
\hline Abuse in childhood - present & -0.015 & -0.057 & -0.064 \\
\hline Discrimination - present & -0.066 & 0.020 & 0.002 \\
\hline Relatives with problems - present & -0.006 & -0.025 & -0.028 \\
\hline Depression - present & -0.346 & -0.263 & -0.386 \\
\hline Higher AUDIT score & -0.006 & 0.004 & 0.031 \\
\hline Anxiety disorders - present & -0.196 & -0.214 & -0.167 \\
\hline Higher number of chronic diseases & -0.015 & 0.023 & -0.054 \\
\hline
\end{tabular}

PCS - physical component score; MCS - mental component score; bold: $p \leq 0.05$. Bolded independent variables were statistically significant in all three sequences. $F_{0}=24.06, p_{0}<0.001 ; F_{6}=23.32 ; p_{6}<0.001 ; F_{24}=21.05 ; p_{24}<0.001$.

\section{Predictors of improved mental component score of HRQOL}

The mean MCS at baseline was 49.80 (48.93-50.67) and increased to 53.14 (52.37-53.91); the mean PCS was 42.28 (41.41-43.15) and increased to 44.68 (43.82-45.55) during the two year follow-up.

The multivariate modelling was performed sequentially and separately for the first $\left(\mathrm{T}_{0}\right)$, second $\left(\mathrm{T}_{6}\right)$ and third (T24) data collection period $\left(\mathrm{F}_{0}=24.06, \mathrm{p}_{0}<0.001\right.$; $\left.\mathrm{F}_{6}=23.32 ; \mathrm{p}_{6}<0.001 ; \mathrm{F}_{24}=21.05 ; \mathrm{p}_{24}<0.001\right)$ explaining $38.2 \%, 37.4 \%$ and $35.2 \%$ of the variance respectively.

Higher values on the MCS component of HRQOL were associated with social determinants in all three models, i.e. better social support from friends and relatives $\left(\beta_{0}=0.159, \mathrm{p}_{0} \leq 0.001, \beta_{6}=0.133, \mathrm{p}_{6} \leq 0.001, \beta_{24}=\right.$ $\left.0.099, \mathrm{p}_{24}=0.006\right)$, absence of significant life events in the past 12 months $\left(\beta_{0}=-0.071, p_{0}=0.040, \beta_{6}=-0.129\right.$, $\left.\mathrm{p}_{6} \leq 0.001, \beta_{24}=-0.082, \mathrm{p}_{24}=0.018\right)$, satisfactory circumstances in the household $\left(\beta_{0}=0.127, \mathrm{p}_{0} \leq 0.001, \beta_{6}=\right.$ $\left.0.175, \mathrm{p}_{6}<0.001, \beta_{24}=0.091, \mathrm{p}_{24}=0.014\right)$, and with absence of anxiety $\left(\beta_{0}=0.196, \mathrm{p}_{0} \leq 0.001, \beta_{6}=-0.214, \mathrm{p}_{6} \leq\right.$ $\left.0.001, \beta_{24}=-0.167, \mathrm{p}_{24} \leq 0.001\right)$ or depression $\left(\beta_{0}=\right.$ $0.346, \quad p_{0} \leq 0.001, \quad \beta_{6}=-0.263, \quad p_{6} \leq 0.001, \quad \beta_{24=}-0.386$, $\left.\mathrm{p}_{24} \leq 0.001\right)$. Predictors of better MCS are presented in Table 1 .

Predictors of better physical component score of HRQOL A linear regression was conducted for $\mathrm{T}_{0}, \mathrm{~T}_{6}$ and $\mathrm{T}_{24}$ sequentially and separately $\left(\mathrm{F}_{0}=13.57, \mathrm{p}_{0}<0.001 ; \mathrm{F}_{6}=\right.$ $\left.20.75 ; \mathrm{p}_{6}<0.001 ; \mathrm{F}_{24}=23.87 ; \mathrm{p}_{24}<0.001\right), 33.0 \%, 42.9 \%$ and $46.5 \%$ of the variance respectively were explained.

Higher values on the PCS component of HRQOL were in all three models associated with higher educational attainment $\left(\beta_{0}=0.140, p_{0} \leq 0.001, \beta_{6}=0.124\right.$, $\left.\mathrm{p}_{6} \leq 0.001, \beta_{24}=0.096, \mathrm{p}_{24}=0.005\right)$, absence of chronic pain $\left(\beta_{0}=-0.082, p_{0}=0.049, \beta_{6}=-0.141, p_{6} \leq 0.001\right.$, $\left.\beta_{24}=-0.169, \mathrm{p}_{24} \leq 0.001\right)$, depression $\left(\beta_{0}=-0.094, \mathrm{p}_{0}=\right.$ $\left.0.019, \beta_{6}=-0.101, \mathrm{p}_{6}=0.008, \beta_{24}=-0.186, \mathrm{p}_{24} \leq 0.001\right)$ and better health self-evaluation $\left(\beta_{0}=-0.360\right.$, $\mathrm{p}_{0 \leq} 0.001, \quad \beta_{6}=-0.415, \mathrm{p}_{6} \leq 0.001, \quad \beta_{24}=-0.433, \mathrm{p}_{24} \leq$ $0.001)$ together with absence of stressful life events $\left(\beta_{0}=-0.115, \mathrm{p}_{0} \leq 0.001, \beta_{6}=-0.107, \mathrm{p}_{6} \leq 0.001, \beta_{24}=\right.$ $-0.068, \mathrm{p}_{24}=0.034$ ) which is shown in Table 2 .

\section{Discussion}

The presented findings in a prospective cohort of family medicine patients showed a statistically significant change in the mental and physical components of wellbeing at follow-up. Quality of life improved significantly in better educated people with good social support and satisfactory circumstances in their household, the absence of major life events in the past 12 months, good self-assessment of health, and the absence of depression, anxiety disorders and chronic pain (Tables 1 and 2). The results of this longitudinal study expanded the previous evidence from cross-sectional population-based and clinical studies that investigated the association of several variables with HRQOL. 
Table 2 Comparison of $\beta$-coefficients at baseline, after 6 and 24 months: Predictors of better physical component score of HRQOL

\begin{tabular}{|c|c|c|c|}
\hline \multirow[t]{2}{*}{ Independent variables } & $\beta(601)$ & $\beta(601)$ & $\beta(601)$ \\
\hline & 0 months $\left(T_{0}\right)$ & 6 months $\left(T_{6}\right)$ & 24 months $\left(T_{24}\right)$ \\
\hline Better MCS & -0.103 & -0.065 & -0.126 \\
\hline Higher age & -0.140 & -0.197 & -0.071 \\
\hline Male gender & 0.053 & 0.098 & 0.085 \\
\hline Higher level of education & 0.140 & 0.124 & 0.096 \\
\hline Better financial status & 0.102 & 0.047 & 0.049 \\
\hline Unemployed & 0.039 & 0.059 & -0.026 \\
\hline Retired & 0.055 & 0.040 & 0.023 \\
\hline Better circumstances in a household & 0.035 & 0.019 & 0.021 \\
\hline Better social support & 0.050 & 0.080 & 0.051 \\
\hline Stressful life events - present & -0.115 & -0.107 & -0.068 \\
\hline Self-rated health & -0.360 & -0.415 & -0.433 \\
\hline Depression - present & -0.094 & -0.101 & -0.186 \\
\hline Higher AUDIT score & 0.027 & 0.018 & 0.009 \\
\hline Anxiety disorders - present & 0.005 & -0.039 & -0.093 \\
\hline Higher number of chronic diseases & -0.053 & 0.031 & 0.080 \\
\hline Diabetes mellitus - present & $<0.001$ & -0.012 & -0.006 \\
\hline Coronary heart disease - present & -0.026 & -0.045 & -0.060 \\
\hline Chronic pulmonary disease - present & -0.002 & 0.009 & -0.067 \\
\hline Arterial hypertension - present & 0.098 & 0.063 & -0.013 \\
\hline Arthritis - present & -0.030 & -0.042 & -0.087 \\
\hline Chronic pain - present & -0.082 & -0.141 & -0.169 \\
\hline
\end{tabular}

PCS - physical component score; MCS - mental component score; bold: $p \leq 0.05$. Bolded independent variables were statistically significant in all three sequences. $F_{0}=13.57, p_{0}<0.001 ; F_{6}=20.75 ; p_{6}<0.001 ; F_{24}=23.87 ; p_{24}<0.001$.

A change in the mental and physical components of health related quality of life during the follow-up period The rise in MCS and PCS is not in accordance with the previously published body of research [31-34], where a decline in HRQOL over time was shown. However, most of the longitudinal studies have found the MCS remaining relatively stable over time or even improving, while PCS declined with time [35-38]. Longitudinal studies with a longer observation period have shown declines in HRQOL domains. A possible explanation of both PCS and MCS improving over time could lie with the socio-economic context of the country during the data collection period. From 2003 to approximately 2008, there was political stability and economic growth in Slovenia [39]; the country entered the European Union and adopted the euro as the national currency. The increase in HRQOL could therefore be explained by the positive socio-economic situation in the country and the subjective assessment of the HRQOL. It is also likely that it was too short a time period to detect changes in HRQOL due to ageing, which is known to be associated with a lower HRQOL $[15,21,34]$. Since the average participant was middle-aged, apparently no severe health deteriorations occurred during the study period. Finally, the cohort could have received more attention from their physicians; the simple fact that the patient was included in this longitudinal study could have ensured that they were better taken care of. As this would have introduced an additional variable, and would have interfered with the real-life approach of the study, the participating GPs did not receive any specific additional education about HRQOL and its dimensions, or any training in the diagnosis of the health conditions in question. However, the GPs were aware of the patients` voluntary participation in the study, so a Hawthorne effect could have appeared.

\section{Socio-demographic predictors of health related quality of life}

One socio-demographic characteristic, i.e. higher educational attainment, was identified as being associated with better PCS (Table 2), which is in line with other studies [21]. It is worth mentioning that in Slovenia the consultation time for higher-educated patients has been shown to be longer than for less well-educated patients [40]; 
Table 3 Demographic characteristics of patients for the study period

\begin{tabular}{|c|c|c|c|c|}
\hline & & \multicolumn{3}{|c|}{$\mathrm{N}(\%)$} \\
\hline & & 0 months & 6 months & 24 months \\
\hline \multirow[t]{2}{*}{ Gender } & Male & $215(35.8 \%)$ & $215(35.8 \%)$ & $215(35.8 \%)$ \\
\hline & Female & $386(64.2 \%)$ & $386(64.2 \%)$ & $386(64.2 \%)$ \\
\hline \multirow[t]{2}{*}{ Nationality } & Slovenian & $548(91.2 \%)$ & $544(90.5 \%)$ & $592(98.5 \%)$ \\
\hline & Other & $53(8.8 \%)$ & $57(9.5 \%)$ & $9(1.5 \%)$ \\
\hline \multirow[t]{2}{*}{ Religiosity } & Yes & $374(62.2 \%)$ & $389(64.7 \%)$ & $408(67.9 \%)$ \\
\hline & No & $227(38.8 \%)$ & $212(35.3 \%)$ & $193(32.1 \%)$ \\
\hline \multirow[t]{3}{*}{ Employment status } & Employed & $332(53.6 \%)$ & $363(60.4 \%)$ & $357(59.4 \%)$ \\
\hline & Unemployed, student & $60(10.0 \%)$ & $62(10.3 \%)$ & $49(8.2 \%)$ \\
\hline & Retired & $216(35.9 \%)$ & $175(29.1 \%)$ & $195(32.4 \%)$ \\
\hline \multirow[t]{3}{*}{ Educational level } & Up to elementary school & $132(22.0 \%)$ & $122(20.3 \%)$ & $117(19.5 \%)$ \\
\hline & High school & $367(61.1 \%)$ & $375(62.4 \%)$ & $369(61.4 \%)$ \\
\hline & College and higher & $102(17.0 \%)$ & $104(17.3 \%)$ & $112(18.6 \%)$ \\
\hline \multirow[t]{4}{*}{ Self-rated financial status } & Major financial problems & $15(2.5 \%)$ & $10(1.7 \%)$ & $12(2.0 \%)$ \\
\hline & Minor financial problems & 77 (12.8\%) & $76(12.6 \%)$ & $71(11.8 \%)$ \\
\hline & Comfortable living & $473(78.7 \%)$ & $480(79.9 \%)$ & $474(78.9 \%)$ \\
\hline & Very comfortable living & $36(6.0 \%)$ & $35(5.8 \%)$ & $44(7.3 \%)$ \\
\hline \multirow[t]{2}{*}{ Marital status } & Married or living with partner & $423(70.4 \%)$ & $422(70.2 \%)$ & $416(69.2 \%)$ \\
\hline & Single & $175(29.1 \%)$ & $176(29.3 \%)$ & $181(30.1 \%)$ \\
\hline
\end{tabular}

getting more attention and medical information or guidance could affect HRQL. Aside from the amount of given advice, level of education was identified as a relevant predictor of recall in Slovenian family medicine patients, although level of education alone does not reflect memory potential [41].

A better MCS component of HRQOL was associated with better social support and the absence of significant life events (Table 1), and the same pattern was shown to be associated with better PCS (Table 2). Good social support was shown to be a protective factor $[42,43]$, while significant life events as stressors were shown to be associated with a lower MCS component of HRQOL, concordant with other findings [44-46].

\section{Health predictors of health related quality of life}

Depression was associated with the MCS as well as the PCS component of HRQOL (Tables 1 and 2), while anxiety was associated only with the MCS component of HRQOL (Table 1). Mental health problems are considered as even more important than physical problems with regard to quality of life perception and assessment [47-49]. Self-rated health has been shown to be highly associated with the PCS component of HRQL, as also found by other authors [50,51]. Aside from chronic pain being associated with the PCS component of HRQOL (Table 2), concordant with findings of other researchers [52-56], we did not find statistically significant associations between chronic diseases and either the PCS or MCS component of HRQOL as others did [22,57]. A cross-sectional study performed in 2011 in Slovenia showed a significantly higher prevalence of chronic diseases in those with a lower socio-economic status and in pensioners [58]. Since level of education has been shown to be associated with socioeconomic status in the Slovenian active population [59], the explanation could lie partially in this characteristic. Selic and co-workers [60] reported the burden of somatic co-morbidity to be smaller than the impact of psychosocial determinants when identifying the patterns of physical co-morbidity and factors associated with the onset of depression. Psychosocial determinants, i.e. the feeling of safety at home and the absence of problems in intimate relationships, were interpreted as protective factors [60]. On the other hand, in a longitudinal study of the predictors of HRQOL in patients with arterial hypertension, Maatouk and colleagues reported most of the somatic diseases to be associated with a lower PCS after five years [61]. Due to the quality of data collected, in this study the impact of neither the severity of chronic somatic disease nor the time since diagnosis could be shown, although these are known to have a particular impact on HRQOL according to patients' adaptation to disease, as stated by Schwartz and Sprangers in the response shift theory $[62,63]$. We embrace the explanation that individuals experiencing a change in their health status may also 
Table 4 Social determinants of patients for the study period

\begin{tabular}{|c|c|c|c|c|}
\hline & & \multicolumn{3}{|c|}{$\mathrm{N}(\%)$} \\
\hline & & 0 months & 6 months & 24 months \\
\hline \multirow[t]{2}{*}{ Household } & Living alone & $64(10.6 \%)$ & $62(10.3 \%)$ & $63(10.5 \%)$ \\
\hline & Living with someone & $536(89.2 \%)$ & $536(89.2 \%)$ & $538(89.5 \%)$ \\
\hline Stressful life events & Present & $309(51.4 \%)$ & $259(43.1 \%)$ & $292(48.6 \%)$ \\
\hline Abuses in childhood & Present & $126(21.0 \%)$ & $89(14.8 \%)$ & $100(16.6 \%)$ \\
\hline Discrimination & Present & $46(7.7 \%)$ & $32(5.3 \%)$ & $29(4.8 \%)$ \\
\hline Relatives with problems & Present & $114(19.0 \%)$ & $97(16.1 \%)$ & $97(16.1 \%)$ \\
\hline Circumstances in a household & M (95\% confidence interval) $1-5$ ( $5=$ very satisfactory $)$ & $4.28(4.21-4.34)$ & $4.30(4.24-4.37)$ & $4.32(4.26-4.39)$ \\
\hline $\begin{array}{l}\text { Social support of family } \\
\text { and friends }\end{array}$ & $\begin{array}{l}\text { M (95\% confidence interval) } 7-21 \\
\text { (21 = excellent personal relationships) }\end{array}$ & $18.77(18.55-18.99)$ & $19.01(18.78-19.23)$ & $19.34(19.12-19.55)$ \\
\hline
\end{tabular}

Legend: $M$ - mean.

change their appraisals, internal standards and values with regard to QOL and will try to further research possible associations.

In the multivariate modelling conducted for $\mathrm{T}_{0}, \mathrm{~T}_{6}$ and $\mathrm{T}_{24}$ sequentially and separately, $38.2 \%, 37.4 \%$ and $35.2 \%$ of the variance respectively were explained for the MCS and $33.0 \%, 42.9 \%$ and $46.5 \%$ of the variance respectively were explained for the PCS of HRQL. The strength of identified predictors for PCS is therefore greater compared to predictors of MCS, although the absence of depression and stressful life events in the previous year acted as the most important predictors of HRQL as a whole. Further research is needed to be able to explain more of the total variance, also considering that this study was limited by its reliance on self-reported data (questionnaires on quality of life, depression, anxiety disorders and alcohol consumption), which raises questions about the potential for method variance (i.e. same-source measurement bias) to account for our findings. Although the phenomena being studied could have been assessed only by questionnaire administration, asking respondents to report an internal state or perception, it would be useful in the design of further research if some other measures were incorporated to mitigate the potential effects of method variance.

\section{Strengths and limitations of the study}

One of the major strengths of our study is longitudinal follow-up of the patient cohort providing three consecutive measurements of HRQOL and the variables associated with it. Moreover, the study was performed on a representative sample of family medicine patients. The data about patients' chronic diseases were obtained from their medical records, which is more accurate than patients' self reports.

Aside from the reliance on mostly self-reported data, a possible limitation to the study could be the missing data, since only about half of the original cohort was included in the analysis. However, given that there were no statistically significant differences in any of the analysed variables with the initial cohort except for gender, we believe that the initially planned representativeness of the sample was not lost.

In spite of the large sample size, the prevalence of depression (93 (15.5\%)), anxiety disorder (49 (8.2\%)) and

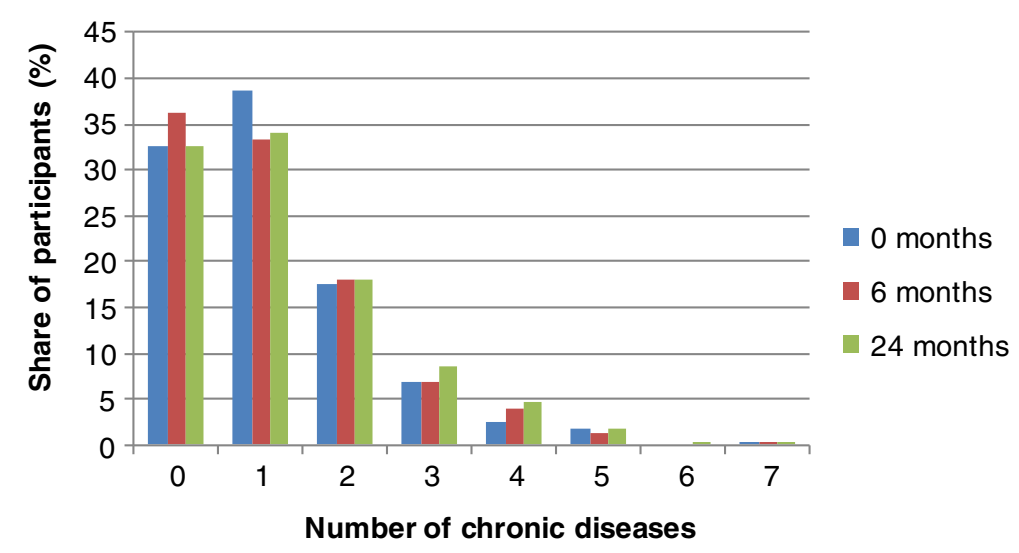

Figure 2 Multi-morbidity in patients for the study period. 
Table 5 Self-rated health, presence of chronic somatic and mental diseases in patients for the study period

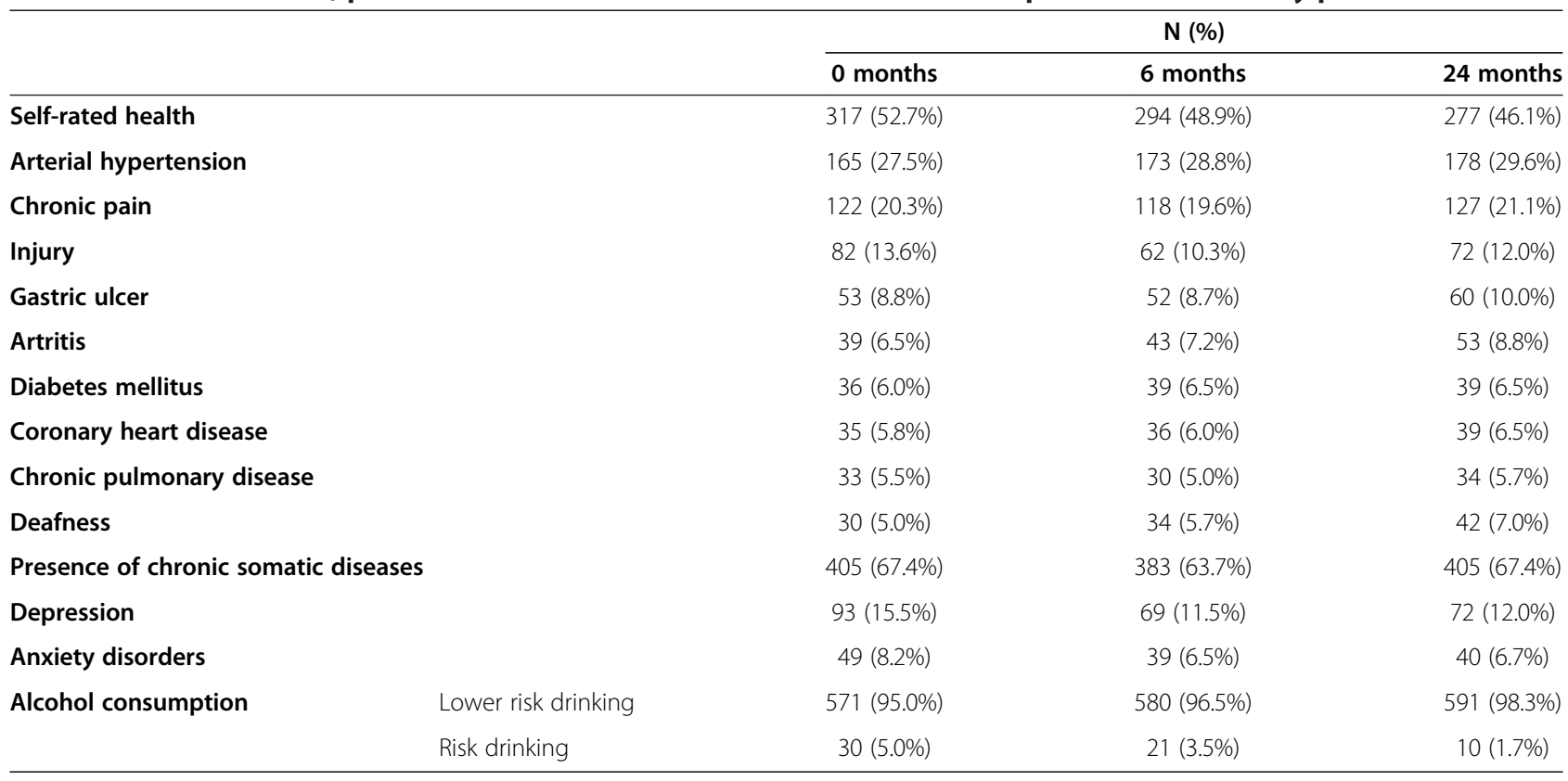

harmful alcohol drinking (30 (5.0\%)) (Table 5) was lower than in previous research in Slovenia $[30,60]$ and resulted in a low number of subjects with common mental disorders. In comparison to a representative sample of Slovenian general practice attendees, described by Svab and coworkers [58], the patients in our sample were younger (at baseline 48.6 and after 24 months $50.4 v s$. 51.7 years of age), better educated (primary school $22 \%$ vs. $41 \%$; high school $62 \%$ vs. $48 \%$; college or university degree $17 \%$ vs. $11 \%)$, with a higher proportion of women $(64.2 \%$ vs. $54.8 \%)$. Aside from the latter, all the above-mentioned characteristics of the sample were apparently in favour of this lower prevalence; nevertheless, further research should be carried out to validate the prevalence data.

Furthermore, only information of the presence or absence of chronic diseases was obtained, without data on their severity or complications, which have been shown to be associated with HRQOL. Since the physicians were aware of the patients 'voluntary participation in the study, a non-specific influence of study participation on their usual care patterns should be considered with regard to the identification of chronic diseases and their treatment in the cohort. Finally, information about the time since diagnosis was not taken into account in the analysis, but is expected to be associated with HRQOL.

\section{Conclusions}

In order to improve HRQOL in patients, GPs should pay attention to the timely recognition and management of depression and anxiety and also chronic pain, as depression can intensify the feeling of chronic pain, while living with chronic pain can contribute to depression.
The symptoms of chronic pain, depression and anxiety often overlap in patients.

Moreover, GPs should have a good insight in the social support system and satisfaction with household circumstances of their patients, and take into account education levels, both of which contribute to HRQOL. Since the level of education is marked on patients ' medical charts, it would be possible for GPs to take this characteristic into consideration when providing either more complex or a larger volume of medical information, or trying to empower patients regarding HRQL. Although GPs are not able to control stressful life events affecting their patients, they can explore patients` coping mechanisms and provide information about active, rather than passive, coping strategies.

\section{Abbreviations}

QOL: Quality of life; HRQOL: Health-related quality of life; MCS: Mental component score; PCS: Physical component score; CIDI: Depression section of the composite international diagnostic interview; DSM-IV: Diagnostic and statistical manual of mental disorders; PHQ: Patient health questionnaire; AUDIT: Alcohol use disorders identification test.

\section{Competing interests}

The authors declare that they have no competing interests.

\section{Authors' contributions}

AC participated in the study execution, contributed to the data analysis and participated in drafting the manuscript. IS conceived the study and participated in the data interpretation. JK participated in data collection and interpretation. PS participated in the design of the study, carried out the coordination of the study, and drafted the manuscript. All the authors read and approved the final manuscript.

Authors' information

AC: PhD Family Medicine, Junior Researcher at the Department of Family Medicine. 
IS: PhD Family Medicine, Professor, Head of the Department of Family Medicine.

JK: PhD Family Medicine, Professor, Head of the Research Division at the Department of Family Medicine.

PS: PhD Clinical Psychology, Senior Researcher and Assistant Professor at the Department of Family Medicine.

\section{Acknowledgements}

The study was partly supported by the Slovenian Research Agency, Research Programme Code P3-0339. The Slovenian Research Agency did not affect any decisions of the authors and did not influence the study design and execution in any way.

Authors are grateful to the patients and physicians who took part in the study.

Special thank is to be dedicated to Professor Anuska Ferligoj for her valuable advice and guidance in data analysis.

Received: 14 November 2012 Accepted: 26 November 2013

Published: 10 December 2013

\section{References}

1. Alonso J, Ferrer M, Gandek B, Ware JE Jr, Aaronson NK, Mosconi P, Rasmussen NK, Bullinger M, Fukuhara S, Kaasa S, Leplège A: Health-related quality of life associated with chronic conditions in eight countries: results from the international quality of life assessment (IQOLA) project. Qual Life Res 2004, 13:283-298.

2. Coons SJ, Rao S, Keininger DL, Hays RD: A comparative review of generic quality-of-life instruments. Pharmacoeconomics 2000, 17(1):13-35.

3. The World Health Organization Quality of Life Assessment (WHOQOL): Development and General Psychometric Properties. Soc Sci Med 1998, 46:1569-1585.

4. Farquhar M: Definitions of quality of life: a taxonomy. J Adv Nurs 1995, 22:502-508

5. Howes CJ, Reid MC, Brandt C, Ruo B, Yerkey MW, Prasad B, Lin C, Peduzzi P, Ezekowitz MD: Exercise tolerance and quality of life in elderly patients with chronic atrial fibrillation. J Cardiovasc Pharmacol Ther 2001, 6:23-29.

6. Xuan J, Kirchdoerfer LJ, Boyer JG, Norwood GJ: Effects of comorbidity on health-related quality-of-life score: an analysis of clinical trial data. Clin Ther 1999, 21:383-403.

7. Prutkin JM, Feinstein AR: Quality-of-life measurements: origin and pathogenesis. Yale J Biol Med 2002, 75:79-93.

8. Testa MA, Simonson DC: Assesment of quality-of-life outcomes. N Engl J Med 1996, 334:835-840.

9. Wilson IB, Cleary PD: Linking clinical variables with health-related quality of life. A conceptual model of patient outcomes. JAMA 1995, 273:59-65.

10. Serrano-Aguilar $P$, Ramallo-Fariña $Y$, Trujillo-Martín Mdel M, Muñoz-Navarro SR, Perestelo-Perez L, De-las-Cuevas-Castresana C: The relationship among mental health status (GHQ-12), health related quality of life (EQ-5D) and health-state utilities in a general population. Epidemiol Psichiatr Soc 2009, 18:229-239.

11. Ormel J, VonKorff M, Ustun TB, Pini S, Korten A, Oldehinkel T: Common mental disorders and disability across cultures. Results from the WHO Collaborative Study on Psychological Problems in General Health Care. JAMA 1994, 272:1741-1748.

12. Alonso J, Angermeyer MC, Bernert S, Bruffaerts R, Brugha TS, Bryson H, de Girolamo G, Graaf R, Demyttenaere K, Gasquet I, Haro JM, Katz SJ, Kessler RC, Kovess V, Lépine JP, Ormel J, Polidori G, Russo LJ, Vilagut G, Almansa J, Arbabzadeh-Bouchez S, Autonell J, Bernal M, Buist-Bouwman MA, Codony M, Domingo-Salvany A, Ferrer M, Joo SS, Martínez-Alonso M, Matschinger H, Mazzi F, Morgan Z, Morosini P, Palacín C, Romera B, Taub N, Vollebergh WA: Disability and quality of life impact of mental disorders in Europe: results from the European Study of the Epidemiology of Mental Disorders (ESEMeD) project. Acta Psychiatr Scand Suppl 2004, 420:38-46.

13. Judd LL, Akiskal HS, Zeller PJ, Paulus M, Leon AC, Maser JD, Endicott J, Coryell W, Kunovac JL, Mueller TI, Rice JP, Keller MB: Psychosocial disability during the long-term course of unipolar major depressive disorder. Arch Gen Psychiatry 2000, 57:375-380.

14. Stein MB, Heimberg RG: Well-being and life satisfaction in generalized anxiety disorder: comparison to major depressive disorder in a community sample. J Affect Disord 2004, 79:161-166
15. Brazier JE, Harper R, Jones NM, O'Cathain A, Thomas KJ, Usherwood T, Westlake L: Validating the SF-36 health survey questionnaire: New outcome measure for primary care. BMJ 1992, 305:160-164.

16. Garratt AM, Ruta DA, Abdalla MI, Buckingham JK, Russell IT: The SF-36 health survey questionnaire: An outcome measure suitable for rutine use with the NHS? BMJ 1993, 306:1440-1444.

17. Jenkinson C, Coulter A, Wright L: Short Form 36 (SF36) health survey questionnaire: Normative data for adults of working age. BMJ 1993, 306:1437-1440.

18. Fortin M, Lapointe L, Hudon C, Vanasse A, Ntetu AL, Maltais D: Multimorbidity and quality of life in primary care: a systematic review. Health Qual Life Outcomes 2004, 2:51.

19. Zalihić A, Markotić V, Zalihić D, Mabić M: Gender and quality of life after cerebral stroke. Bosn J Basic Med Sci 2010, 10:94-99.

20. Lippmann QK, Crockett SD, Dellon ES, Shaheen NJ: Quality of life in GERD and Barrett's esophagus is related to gender and manifestation of disease. Am J Gastroenterol 2009, 104:2695-2703.

21. Zahran HS, Kobau R, Moriarty DG, Zack MM, Holt J, Donehoo R: Healthrelated quality of life surveillance-United States, 1993-2002. MMWR Surveill Summ 2005, 54:1-35.

22. Walker AE: Multiple chronic diseases and quality of life: patterns emerging from a large national sample, Australia. Chronic IIIn 2007, 3:202-218

23. Farkas J, Pahor M, Zaletel-Kragelj L: Self-rated health in different social classes of Slovenian adult population: nationwide cross-sectional study. Int J Public Health 2011, 56:45-54

24. King M, Weich S, Torres-González F, Svab I, Maaroos HI, Neeleman J, Xavier M, Morris R, Walker C, Bellón-Saameño JA, Moreno-Küstner B, Rotar D, Rifel J, Aluoja A, Kalda R, Geerlings MI, Carraça I, de Almeida MC, Vicente B, Saldivia S, Rioseco P, Nazareth I: Prediction of depression in European general practice attendees: the PREDICT study. BMC Public Health 2006, 6:6

25. King M, Walker $C$, Levy $G$, Bottomley $C$, Royston $P$, Weich $S$, Bellón-Saameño JA, Moreno B, Svab I, Rotar D, Rifel J, Maaroos HI, Aluoja A, Kalda R, Neeleman J, Geerlings MI, Xavier M, Carraça I, Gonçalves-Pereira M, Vicente B, Saldivia S, Melipillan R, Torres-Gonzalez F, Nazareth I: Development and validation of an international risk prediction algorithm for episodes of major depression in general practice attendees: the PredictD study. Arch Gen Psychiatry 2008, 65:1368-1376.

26. Jenkinson C, Layte R, Jenkinson D, Lawrence K, Petersen S, Paice C, Stradling J: A shorter form health survey: can the SF-12 replicate results from the SF-36 in longitudinal studies? J Public Health Med 1997, 19:179-186.

27. Kessler RC, Ustun TB: The World Mental Health (WMH) Survey Initiative Version of the World Health Organization (WHO) Composite International Diagnostic Interview (CIDI). Int J Methods Psychiatr Res 2004, 13:93-121.

28. Spitzer RL, Kroenke K, Williams JB: Validation and utility of a self-report version of PRIME-MD: the PHQ primary care study. Primary care evaluation of mental disorders: patient health questionnaire. JAMA 1999, 282:1737-1744.

29. Barbor TF, de la Fuente JR, Saunders J, Grant M: Development of the Alcohol Use Disorders Identification Test (AUDIT): WHO Collaborative Project on Early Detection of Persons with Harmful Alcohol Consumption-II. Addiction 1993, 88:791-804.

30. Klemenc-Ketis Z, Kersnik J, Tratnik E: The presence of anxiety and depression in the adult population of family practice patients with chronic diseases. Zdrav Var 2009, 48:170-176.

31. Hopman WM, Berger C, Joseph L, Towheed T, VandenKerkhof E, Anastassiades T, Adachi JD, loannidis G, Brown JP, Hanley DA, Papadimitropoulos EA: The natural progression of health-related quality of life: Results of a five-year prospective study of SF-36 scores in a normative population. Qual Life Res 2006, 15:527-536.

32. Hopman WM, Berger C, Joseph L, Towheed T, vanden Kerkhof E, Anastassiades T, Cranney A, Adachi JD, loannidis G, Poliquin S, Brown JP, Murray TM, Hanley DA, Papadimitropoulos M, Tenenhouse A: Stability of Normative Data for the SF-36 Health Survey: Results of a three-year prospective study in middle-aged Canadians. Can J Public Health 2004, 95:387-391.

33. Solari A, Ferrari G, Radice D: A longitudinal survey of self-assessed health trends in a community cohort of people with multiple sclerosis and their significant others. J Neurol Sci 2006, 243:13-20.

34. Hazell ML, Morris JA, Linehan MF, Frank TL: Temporal change in health-related quality of life: a longitudinal study in general practice 1999-2004. Br J Gen Pract 2009, 59:839-843. 
35. Hopman WM, Coo H, Pavlov A, Day AG, Edgar CM, McBride EV, Brunet DG: Multiple Sclerosis: Change in Health-Related Quality of Life Over Two Years. Can J Neurol Sci 2009, 36:554-561.

36. Miller DM, Rudick RA, Baier M, Cutter G, Doughtery DS, Weinstock-Guttman $B$, Mass MK, Fisher E, Simonian N: Factors that predict health-related quality of life in patients with relapsing-remitting multiple sclerosis. Mult Scler 2003, 9:1-5.

37. Hopman WM, Coo H, Brunet DG, Edgar CM, Singer MA: Longitudinal assessment of health-related quality of life (HRQOL) of patients with multiple sclerosis. Int J MS Care 2000, 2:15-26.

38. Wandell PE, Brorsson B, Aberg H: Quality of life in relation to comorbidity among diabetic patients followed for three years in Swedish primary health care. Diabetes Metab 1999, 25:424-428.

39. Eurostat - Tables, Graphs and Maps Interface (TGM) table: Real Gross Domestic Product (GDP) Growth Rate - Volume. http://epp.eurostat.ec.europa.eu/ tgm/table.do?tab=table\&init=1\&plugin=1 \&language=en\&pcode=tec00115.

40. Petek Ster M, Svab I, Zivcec KG: Factors related to consultation time: experience in Slovenia. Scand J Prim Health Care 2008, 26:29-34.

41. Selic P, Svab I, Repolusk M, Gucek NK: What factors affect patients' recall of general practitioners' advice? BMC Fam Pract 2011, 12:141.

42. Parker PA, Baile WF, Moor-de C, Cohen L: Psychosocial and demographic predictors of quality of life in a large sample of cancer patients. Psychooncology 2003, 12:183-193.

43. Cohen S, Wills TA: Stress, social support and the buffering hypothesis. Psychol Bull 1985, 98:310-357.

44. Bovier PA, Chamot E, Perneger TV: Perceived stress, internal resources, and social support as determinants of mental health among young adults. Qual Life Res 2004, 13:161-170.

45. Lu Y, Nyunt MS, Gwee X, Feng L, Feng L, Kua EH, Kumar R, Ng TP: Life event stress and chronic obstructive pulmonary disease (COPD): associations with mental well-being and quality of life in a population-based study. BMJ Open 2012, 2:

46. Staniute M, Brozaitiene J, Bunevicius R: Effects of social support and stressful life events on health-related quality of life in coronary artery disease patients. J Cardiovasc Nurs 2013, 28:83-89.

47. Spitzer RL, Kroenke K, Linzer M, Hahn SR, Williams JB, deGruy FV 3rd, Brody D, Davies M: Health-related quality of life in primary care patients with mental disorders. Results from the PRIME-MD 1000 Study. JAMA 1995, 274:1511-1517.

48. Saarni SI, Suvisaari J, Sintonen H, Koskinen S, Härkänen T, Lönnqvist J: The health-related quality-of-life impact of chronic conditions varied with age in general population. J Clin Epidemio/ 2007, 60:1288-1297.

49. Hays RD, Wells KB, Sherbourne CD, Rogers W, Spritzer K: Functioning and well-being outcomes of patients with depression compared with chronic general medical illnesses. Arch Gen Psychiatry 1995, 52:11-19.

50. Tomori M, Ziherl S: Psihiatrija. Ljubljana: Litterapicta Ljubljana; 1999

51. Olomu AB, Corser WD, Stommel M, Xie Y, Holmes-Rovner M: Do self-report and medical record comorbidity data predict longitudinal functional capacity and quality of life health outcomes similarly? BMC Health Serv Res 2012, 12:398.

52. Australian Institute of Health and Welfare: Chronic Diseases and Associated Factors in Australia 2001. Canberra: Australian Institute of Health and Welfare (AlHW); 2002.

53. Juenger J, Schellberg D, Kraemer S, Haunstetter A, Zugck C, Herzog W, Haass M: Health related quality of life in patients with congestive heart failure: comparison with other chronic diseases and relation to functional variables. Heart 2002, 87:235-241.

54. Piazza JR, Charles ST, Almeida DM: Living with chronic health conditions: age differences in affective well-being. J Gerontol B Psychol Sci Soc Sci 2007, 62:313-321.

55. Michelson $\mathrm{H}$, Bolund $\mathrm{C}$, Brandberg $\mathrm{Y}$ : Multiple chronic health problems are negatively associated with health related quality of life (HRQOL) irrespective of age. Qual Life Res 2000, 9:1093-1104. doi:10.1023/ A:1016654621784.

56. Becker N, Thomsen AB, Olsen AK, Sjogren P, Bech P, Eriksen J: Pain epidemiology and health related quality of life in chronic non-malignant pain patients referred to a Danish multidisciplinary pain center. Pain 1997, 73:393-400

57. Hobbs FD, Kenkre JE, Roalfe AK, Davis RC, Hare R, Davies MK: Impact of heart failure and left ventricular systolic dysfunction on quality of life: a cross-sectional study comparing common chronic cardiac and medical disorders and a representative adult population. Eur Heart J 2002, 23:1867-1876

58. Svab I, Petek Ster M, Kersnik J, Zivcec Kalan G, Car J: A cross sectional study of performance of Slovene general practitioners (English summary). Zdrav Var 2005, 44:183-192.

59. Selic P, Petek D, Pesjak K: Healthy, but are they satisfied? Factors associated with job satisfaction in professional soldiers of the Slovenian armed forces. J Def Manag 2012, 2:1-8.

60. Selic P, Svab I, Rifel J, Pavlic DR, Cerne A, King M, Nazareth I: The pattern of physical comorbidity and the psychosocial determinants of depression: a prospective cohort study on a representative sample of family practice attendees in Slovenia. Ment Health Fam Med 2011, 8:147-155.

61. Maatouk I, Wild B, Herzog W, Wesche D, Schellberg D, Schöttker B, Müller H, Rothenbacher D, Stegmaier C, Brenner $\mathrm{H}$ : Longitudinal predictors of healthrelated quality of life in middle-aged and older adults with hypertension: results of a population-based study. J Hypertens 2012, 30:1364-1372.

62. Schwartz CE, Sprangers MA: Methodological approaches for assessing response shift in longitudinal health-related quality-of-life research. Soc Sci Med 1999, 48:1531-1548.

63. Sprangers MA, Schwartz CE: Integrating response shift into health related quality of life research: a theoretical model. Soc Sci Med 1999, 48:1507-1515.

doi:10.1186/1471-2458-13-1160

Cite this article as: Cerne et al:: Did past economic prosperity affect the health related quality of life predictors? A longitudinal study on a representative sample of Slovenian family medicine patients. BMC Public Health 2013 13:1160.

\section{Submit your next manuscript to BioMed Central and take full advantage of:}

- Convenient online submission

- Thorough peer review

- No space constraints or color figure charges

- Immediate publication on acceptance

- Inclusion in PubMed, CAS, Scopus and Google Scholar

- Research which is freely available for redistribution 